\title{
$\mathrm{C}^{-} \mathrm{I}$ CONGRESO \\ INTERNACIONAL \\ SOBRE \\ LF_O FOTOGRAFÍA
}

Congreso Internacional sobre Fotografía

UPV, 5 y 6 octubre 2017

Doi: http://dx.doi.org/10.4995/CIFo17.2017.6947

ISBN: 978-84-9048-604-7

\section{"Memoria versus historia en tu propio álbum familiar" (valorando una actividad educativa en Historia de la Fotografía de Ciclo Formativo)}

Francesc Perramon Zapatero

Escuela de Arte y Diseño de la Diputación de Tarragona, francescescola@hotmail.com

\begin{abstract}
We present an educational activity proposed by the author as a teacher of History of Photography at vocational-professional studies level. In this activity students are requested for searching, document and analyse an own family portrait, dated to the first half of the 20th century. The activity reaffirms the pedagogical value of learning with objects and topics close to student's own world.

The activity it's useful too because asks the students for using two types of information about the past: memory tellings and historical documentation. According to P. Nora, Memory and History must be opposite. We can recognize how difficult is for the students to apply this difference properly. Actually, there is a widespread confusion about history and memory meanings, especially nowadays when, in mass media, the truth seems something malleable, and we tend to confuse the objective and the subjective.

Finally we compare this educational activity in relation with the requirements established by the Spanish Official Curricula of History of Photography for Professional Studies. This comparison allows us to review the adequacy of same of the curricular requirements at this specific educational level in which they should be implemented.
\end{abstract}

Keywords: photographic portrait, education, family, teaching and learning plan, carte de visite, Pierre Nora, Disdéri, vocational studies

\footnotetext{
Resumen

Presentamos una actividad educativa propuesta por el autor como docente de Historia de la Fotografía en un Ciclo Formativo Profesional de Fotografía. En dicha actividad se solicita a los estudiantes que busquen, documenten y analicen un retrato familiar fechado hacia la primera mitad del s. XX. Se reafirma el valor pedagógico de centrar el aprendizaje en objetos y temas próximos al entorno que el alumno considera propio.
}

La actividad permite también recurrir a dos tipos de información sobre el pasado: los relatos de memoria y la documentación histórica. Siguiendo a P. Nora se señala la necesidad de diferenciar 
estas dos herramientas de conocimiento del pasado. Se comprueba la dificultad de los estudiantes para abordar dicha diferenciación. Esta dificultad se desarrolla en un contexto general donde la confusión memoria-historia es frecuente, al igual que los medios de comunicación actuales tratan la verdad como algo maleable y a menudo se difumina la diferencia entre lo objetivo y lo subjetivo.

Finalmente comparamos los resultados docentes de esta actividad en relación a los requisitos que establecen los planes de estudio oficiales sobre los objetivos de aprendizaje de la asignatura de Historia de la Fotografía en los ciclos formativos profesionales. Ello nos permite revisar la adecuación de algunos de los requisitos curriculares con respecto al nivel educativo concreto en el que deben implementarse.

Palabras clave: retrato fotográfico, pedagogía, familia, currículum académico, carta de visita, Pierre Nora, Disdéri, estudios profesionales

\section{Introducción}

Mi propósito es presentar y compartir una actividad desarrollada como docente de la asignatura de Historia de la Fotografía de primer curso del Ciclo Formativo de Grado Superior de Fotografía. Nuestro centro es la Escuela de Arte y Diseño de Tarragona, EADT (Diputación de Tarragona). En esta actividad concreta propongo a los estudiantes localizar y analizar un retrato fotográfico de su propio entorno familiar, a poder ser de inicios del s. XX, y próximo al modelo estético de "Carta de Visita" o, en todo caso, un retrato realizado por un profesional de la fotografía. La fotografía seleccionada por cada estudiante (y un resumen del análisis que ha realizado) es compartida entre los alumnos en un foro virtual de acceso restringido a los estudiantes. Asimismo también dedicamos un tiempo en el aula para comentar con ellos los resultados de sus hallazgos y análisis.

\section{Objetivos}

Más allá de describir y valorar esta actividad educativa y sus resultados desde una perspectiva de utilidad pedagógica, a través de ella me propongo debatir también sobre el distinto valor de la historia y de la memoria como herramientas de aproximación al conocimiento del pasado. Existe un amplio debate historiográfico sobre el valor específico de la historia y de la memoria. Resultará pertinente tratar de invocar brevemente este debate (Nora, 1984; Lavabre, 2006). En todo caso, esta actividad educativa permite observar y comprobar las dificultades que actualmente tienen estos estudiantes para diferenciar historia y memoria respecto de un documento tan cercano como es una fotografía familiar. Es muy posible que dichas dificultades hayan existido en períodos anteriores, en todo caso a mí me sugieren una reflexión -admito que de carácter especulativo- sobre el valor de la verdad en el contexto actual, en el cual el relato y lo que algunos medios de comunicación denominan la "posverdad" tienden a desatender con mucha facilidad los datos objetivos y contrastados.

Por otra parte, la valoración del desarrollo de esta actividad educativa concreta también permite debatir sobre diversas dificultades que el marco normativo impone a la enseñanza de la fotografía y de la historia de la fotografia en particular. Dificultades que asumo que están presentes en todos los niveles educativos de una u otra forma, cada uno con su marco normativo correspondiente. En todo caso, la valoración de los logros y fracasos de esta actividad nos servirán para ahondar en las condiciones de la enseñanza de la historia de la 
fotografía en el nivel de los Ciclos Formativos de Grado Superior, como titulación específica destinada a formar profesionales de la fotografía en el sistema educativo español.

\section{Desarrollo de la actividad pedagógica}

La actividad se ha propuesto a los estudiantes en un formato muy parecido en los últimos dos cursos. Nos centraremos en el desarrollo de la actividad del curso más reciente, 2016-17.

El enunciado del ejercicio tal como lo planteamos a los estudiantes (anexo 1) les solicita localizar y analizar una fotografía de retrato comercial de un familiar suyo que se pudiera datar, aproximadamente, entre 1860 y 1936.

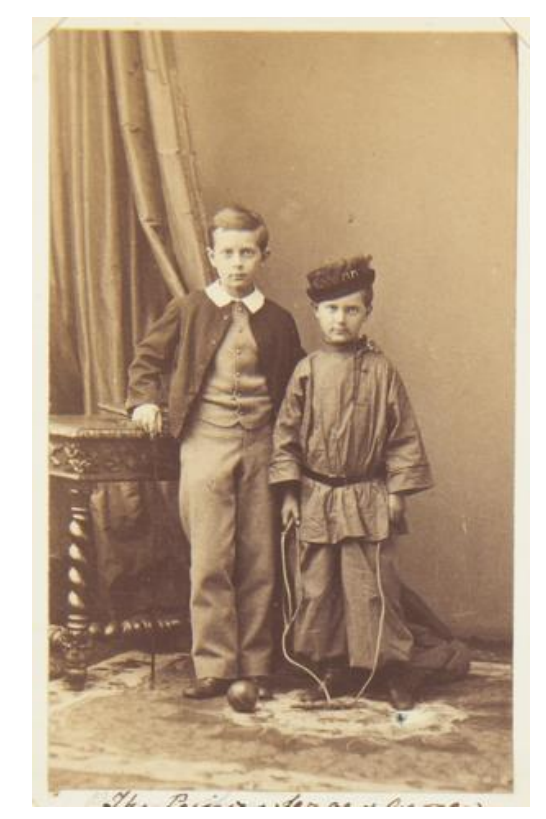

fi. 1

“Principes de Leuchtenberg” (1859), A. Disdéri y Cia. [Colección Real del Reino Unido (via Wikimedia Commons)]

En ese momento del curso, se han abordado ya en clase temas como Alphonse Disdéri y su "Carta de Visita" (figura 1). Ciertamente la historiografía fotográfica ha tratado tradicionalmente a Alphonse Disdéri como un autor ampliamente referenciado. Es el inventor de la "Carta de Visita", un formato técnico y estético que se interpreta como un elemento clave para la democratización del retrato fotográfico entre las clases medias y populares de la Europa de finales del s. XIX. Son retratos fotográficos elaborados en estudio y que se presentan en copias de tamaño pequeño. Muestran un característico plano largo que retrata al individuo con poses encorsetadas y rodeadas de atrezzo que pretende evocar lujo (cortinajes, balaustradas, alfombras, fondos ilusorios...). A menudo se opone la fórmula de la "Carta de Visita" a los retratos fotográficos elaborados por Nadar, considerados más "artísticos" y con soluciones estéticas más sutiles y creativas (Newhall, 1982, 2001, p. 64 y ss.; Freund, 1974, p. 55 y ss.; Sougez, 1996, p. 148 y ss). Así pues, los alumnos saben que el retrato fotográfico se generaliza ampliamente en Europa hacia finales del s. XIX con una estrategia técnica y comercial 
en cierta medida "low cost", vinculada a Disdéri y su "carta de visita", y a al enfoque que más adelante se adjetivaría de taylorista -en serie- del proceso de obtención y venta del retrato fotográfico de estudio.

Nuestros alumnos disponen de unas cinco semanas para analizar su propia "carte de visite" familiar o similar. La primera reacción de los estudiantes a este enunciado es siempre de cierto asombro, casi incredulidad. "Mi familia es una familia «normal», no tenemos fotos tan antiguas como las familias ricas: no podemos hacer este trabajo!", acostumbra a ser la reacción inmediata de muchos estudiantes. De hecho, al tratar la "Carta de Visita" en las clases anteriores siempre llevo algunos "originales" de retratos de mi familia de los años 1920-1930. Son fotografías que mantienen la mayoría de códigos estéticos que fijó A. Didéri en sus cartas de visita. Trato de que puedan hacerse una idea más directa sobre el tipo de objeto fotográfico que estamos estudiando, mucho más allá de las meras reproducciones digitales en pantalla que siempre resultan distintas y, en cierta forma, alejadas e intangibles. Al llevar al aula esos retratos de mi familia es muy inusual que los alumnos espontáneamente reconozcan haber visto retratos similares en su familia y que los traigan motu propio a la siguiente clase. De alguna forma, el mundo del profesor a estos jóvenes les queda tan alejado como el mundo de los libros que están estudiando. No se plantean que ellos tengan fotografías similares. En consecuencia, al encargar el ejercicio hay que alentarlos a su búsqueda, insistir en que es muy posible que descubran fotografias familiares que desconocían, relativizar las exigencias del encargo, decirles que no seremos estrictos con el marco temporal fijado, hablarles de la familia como un grupo social amplio que puede ir más allá de la familia nuclear actual y que, incluso, una búsqueda infructuosa también es un aprendizaje relevante para un historiador. Comprobar que algo no existe también es un avance científico.

En apenas unas semanas los resultados de la búsqueda de los estudiantes resultan exitosos, hallan auténticas joyas históricas y fotográficas. Los primeros sorprendidos son los propios estudiantes. Por ejemplo, en el curso 2016/17 catorce estudiantes presentaron este ejercicio: ocho de las fotografias se ajustaban exactamente a la petición inicial (fotografías de estudio

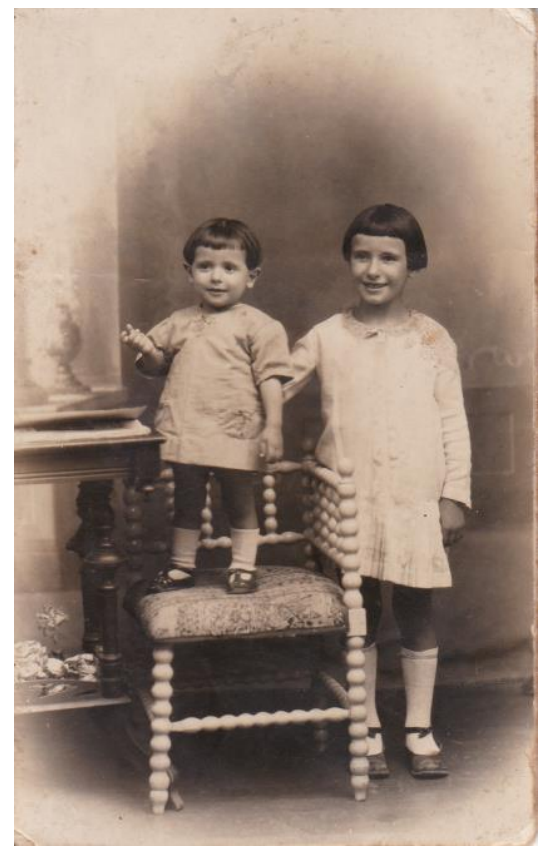

fig. 2

“Hijos Fusté Domènech” (ca. 1930). E. Torres, Reus. [cedida por la estudiante de la EADT Marina López] 
profesional, de un familiar, fechadas en la primera mitad del s. XX, en un formato estético próximo a la carta de visita, etc). La Fig. 2 es un ejemplo de una de estas imágenes. Otras tres de las fotografias corresponden a retratos de primer plano, que si bien se alejan del modelo inicial de la Carta de Visita, resultan igual de ilustrativas de los modelos estéticos, comerciales y sociales que han marcado el retrato fotográfico comercial en España y Europa. Por ejemplo la fotografía de la Fig. 3. presenta un retrato en primer plano. Está fechada entre 1936 y 1938, y además de contener una historia familiar apasionante -que implicó apartar intencionadamente la fotografía de los espacios nobles de la casa- ilustra a los estudiantes el uso de la fotografía "iluminada", pintada a mano, y su estética que ahora nos resulta tan artificial y pictorialista (mientras que actualmente aceptamos el uso de filtros fotográficos nada sutiles en "instagram" sin reparar, también, en su extraordinaria artificialidad).

Solo dos de las imágenes quedaban fuera del encargo inicial y, cada una a su manera, contribuyeron también al aprendizaje del grupo de alumnos, mostrando particularidades interesantes fuera de la situación normativa inducida por el profesor y por el planteamiento

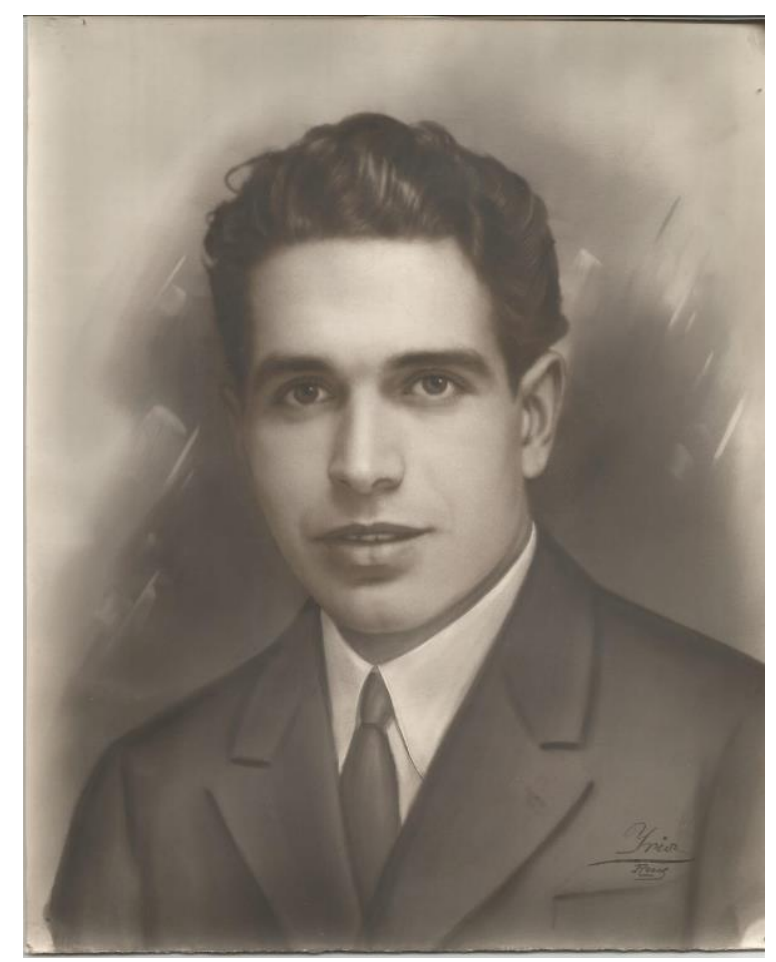

fig. 3

“Joaquim Ulldemolins Pino" (ca 1936-38). Yris (?), Reus. [cedida por la estudiante de la EADT Nadia Darmoun]

del ejercicio. En un primer caso, una alumna solo pudo localizar como retrato familiar antiguo un retrato de su tío abuelo de inicios de los años 1970. En dicha imagen el sujeto aparecía de cuerpo entero detrás de una pared lisa de color claro, con seguridad en el mismo cuartel donde cumplía el servicio militar, tal como indicaba su uniforme. No era posible discernir si se trataba de un retrato doméstico elaborado por un amigo o bien un trabajo de un fotógrafo profesional realizado fuera de estudio, sin más iluminación que la natural de aquel espacio. Todos los estudiantes al visualizar este retrato en el aula repararon en la expresión relajada y sonriente del sujeto, en las antípodas de las expresiones más bien severas, serias, dignas que tratan de mostrar el resto de sujetos (sobre todo adultos) en los retratos profesionales que habíamos visto hasta el momento. Este cambio en la expresión nos permitió hablar de la diferencias entre el retrato profesional y el retrato doméstico, de la 


\section{"Memoria versus historia en tu propio álbum familiar"}

familiaridad con la cámara y el proceso fotográfico de un sujeto occidental de los años 1970, e incluso de la relajación de las costumbres sociales en Occidente desde finales de los años 1950 e inicios de los 60, donde la proximidad y la espontaneidad son vistos como valores sociales positivos, adecuados para mostrar en público. En un segundo caso, otra estudiante después de una búsqueda infructuosa dentro su entorno familiar y, siguiendo una sugerencia del profesor, se aventura en un mercadillo callejero de objetos antiguos y adquiere una bella carta de visita de inicios del s. XX por apenas $3 €$. En este caso, como docente, nuestra evaluación se centra en su capacidad para analizar la imagen, sus códigos técnicos, estéticos e históricos. Lo llamativo de este segundo caso es que la vendedora del mercadillo le explica a la estudiante que el retrato es de su familia (la fotografía está realizada en Barcelona y el mercadillo está en Reus, una localidad a 100km de distancia???), le da el nombre de la fotografiada y diversos datos biográficos, sin ninguna prueba de veracidad al respecto. La estudiante, significativamente, refiere todos esos datos en su trabajo como datos históricos ciertos. Está claro que no formamos historiadores, únicamente profesionales de la fotografia que deben tener unos conocimientos mínimos de historia de este medio visual, pero sin duda llama la atención cómo toman por datos históricos informaciones cuando menos dudosas.

En todo caso los resultados pedagógicos del ejercicio son francamente positivos. Más allá de las dudas iniciales que nos pueden asaltar sobre si los estudiantes podrán encontrar fotografías dentro de las condiciones del encargo e, incluso, más allá del resultado positivo de su búsqueda, lo significativo del ejercicio es que los análisis de los estudiantes sobre cada imagen denotan implicación y motivación por su parte, además de un aprendizaje significativo de buena parte de los códigos implícitos en el retrato fotográfico comercial. En muchos casos se percibe emoción al descubrir la historia a través de su propia familia, por ejemplo al comprender mejor el significado de la postguerra. No cabe duda que abordar el aprendizaje a partir de referentes que resultan próximos siempre es motivador para el alumno. Se evita que el estudiante vea la historia de la fotografía como algo ajeno, que solo afecta a entornos sociales lejanos y abstractos.

Desde una perspectiva historiográfica también resulta muy interesante analizar cómo en esta actividad pedagógica se visualizan las dificultades para discernir los valores distintos de la historia y de la memoria como fuentes de conocimiento del pasado. En ámbitos muy diversos se produce también un uso confuso de ambos términos. Nuestros alumnos, por tanto, no pueden abstraerse de esta confusión generalizada. Baste señalar que tanto en el ámbito jurídico español como catalán existen sendas leyes de "memoria histórica" (Ley 52/2007 o bien el artículo 54 del Estatuto de Autonomía de Cataluña de 2006 sobre memoria histórica, que posteriormente da lugar a la ley catalana 13/2007). Para muchos historiadores, en cambio, la propia expresión "memoria histórica" constituye un oxímoron, son dos conceptos completamente antitéticos, irreconciliables (Massot, 2012). Es cierto, sin embargo, que esta confrontación entre ambos conceptos es relativamente reciente en el debate histórico y está muy vinculada a la repercusión de los textos de Pierre Nora en la década de 1980. Nora opone los conceptos de historia y memoria: "Memoria, historia: lejos de ser sinónimos, tomamos consciencia de que todo las opone. La memoria es la vida, sostenida por los grupos de personas vivas y, por tanto, está en evolución permanente, abierta a la dialéctica del recuerdo y de la amnesia, inconsciente de sus sucesivas deformaciones, vulnerable a todas las utilizaciones y manipulaciones, susceptible a largas latencias y a repentinas revitalizaciones. La historia es la reconstrucción siempre problemática e incompleta, de aquello que ya no es...." (Nora, 1984, p. XIX) (citado también por: Antich, 2011; Cosci, 2012, etc.). Memoria e historia son dos instrumentos valiosos para acercarse al pasado, pero con sentidos, caminos y perspectivas distintas, casi opuestas. La memoria es un acto subjetivo y creativo de cada momento del presente, sin que ello tenga una connotación negativa, siempre que no pretenda confundirse con cuestiones objetivas e históricas (Cross; Peck, 2010; O'Brien, 2010). La historia, contrariamente, es el estudio del pasado, de todo el pasado. La historia no se 
nutre de actos de memoria sino, principalmente, de documentos y otras fuentes de información objetiva (restos materiales, etc.). Se trata de un estudio que persigue la objetividad con metodologías científicas. La historia no pretende comprender el presente (solo el pasado), y todavía menos justificar los actos del presente.

El ejercicio académico que estamos describiendo proponía a los alumnos investigar sobre una fotografía de retrato de su propio entorno familiar. Está claro que es un documento en el que se van a entremezclar de forma muy interesante memoria e historia. El recuerdo que tenemos de nuestros abuelos, originado por las narraciones de ellos mismos, y reelaborados por nuestros padres y nosotros mismos, es sin duda un acto de memoria. Dicho recuerdo es pura subjetividad llena de información, esencialmente del presente, relativa a aquello que ahora nos parece digno de ser explicado en forma y contenido. Existe también mucha información de carácter histórico en relación a este retrato. De una parte tenemos información objetiva sobre nuestro antepasado familiar: su nombre, su fecha de nacimiento, aquello que reflejan sus documentos sobre viajes, actividades económicas... Por otra parte, abstrayéndonos de que se trata de un documento familiar, la fotografia no deja de ser un documento histórico que informa objetivamente sobre procesos fotográficos y hechos sociales y culturales del pasado. En general, también, toda la información sobre el fotógrafo profesional autor de la imagen, ajeno a nuestra memoria familiar, tendrá la consideración de información histórica, a la que accedemos a través de los documentos y de los estudios históricos, no de los relatos subjetivos de nuestra familia.

Como siempre, la realidad se encarga de ser más diversa y compleja que nuestras expectativas iniciales. Una de las alumnas aportó al grupo una fotografía de su bisabuelo (fig. 4) realizada en los años 50 por el fotógrafo Stepàn Nazarenko de la ciudad ucraniana de Ivano-Frankivsk. Lo primero que nos señaló nuestra compañera fue que su bisabuela trabajó toda su vida en este estudio fotográfico retocando los negativos y las copias. Así pues se hizo patente un vínculo de memoria (o posmemoria tal como sugeriría P. Hirsch) en la decisión de esta estudiante de optar por los estudios de fotografía y, lógicamente, por elegir mostrarnos este retrato. A todo el grupo, además, nos ayudó a ejemplificar un hecho histórico: cómo el papel de las mujeres ha sido fundamental y al mismo tiempo silenciado a lo largo de la historia de la fotografía. Desde el siglo XIX es absolutamente frecuente este binomio de género en relación al proceso fotográfico: el operador de la cámara es varón, su trabajo es visible y a él se le atribuye todo el mérito; el trabajo de retoque y copiado es una labor reservada casi íntegramente al género femenino y se desarrolla en la oscuridad de laboratorio, metáfora del silencio que se imprime a su trabajo. Toma y copiado de la imagen son, sin embargo, responsables a partes iguales del resultado final. 


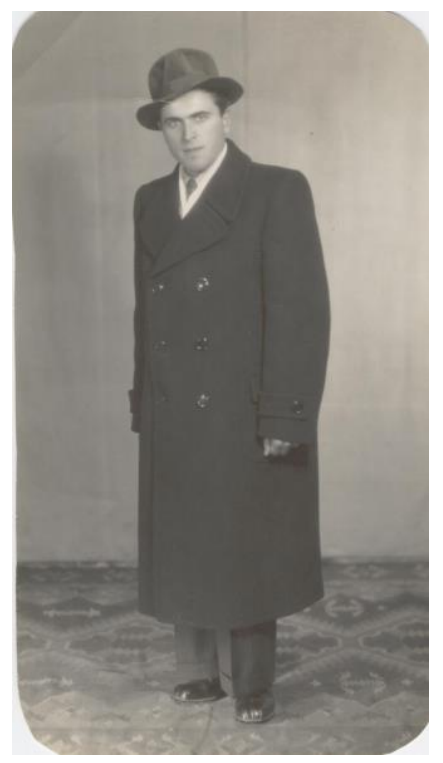

fig. 4

"Mi bisabuelo" (ca 1950). Stepàn Nazarenko, Ivano-Frankivsk, Ucrania. [cedida por la estudiante de la EADT Sofia Shevchuk]

El propio guion del trabajo (anexo 1) proponía a los estudiantes tratar de investigar tanto en relación al fotografiado como en relación al fotógrafo. Se sugería entrevistar a los familiares respecto a la fotografía así como acudir a fuentes de documentación primaria (archivos municipales, revistas de la época, etc.). El objetivo fundamental era que los alumnos elaboraran un comentario detallado del retrato, y que para ello realizaran previamente una breve investigación histórica, documentándose sobre el sujeto fotografiado y sobre el fotógrafo. La documentación recogida iba a contener, muy probablemente, en consecuencia, relatos de memoria y también información histórica. Se pretendía dar relevancia a ambas fuentes. En el encargo se señalaba de forma muy somera: "considerad la posibilidad de diferenciar la información histórica (información objetiva sobre el pasado) de la información de memorias familiares (los recuerdos subjetivos comunicados desde el presente respecto el pasado)". Así pues, no se requiere a los estudiantes que tengan como prioridad diferenciar historia y memoria, sólo se sugiere que consideren sus diferencias y las señalen si lo consideran oportuno. Dado que una parte considerable de la sociedad confunde memoria e historia, incluso en algunos ámbitos académicos, nos parece excesivo exigir esta distinción a nuestros alumnos como criterio básico de evaluación. Son estudiantes que, recordémoslo, tienen como objetivo formarse como profesionales de la fotografía, no como historiadores. En todo caso nos parece muy interesante observar cómo se ha articulado la relación entre lo histórico y lo memorístico en sus trabajos, toda vez que tal distinción ha sido sugerida por el profesor, sin tampoco presionarlos en demasía al respecto.

Para los estudiantes, la fuente de documentación más accesible eran sus familiares, a los que entrevistaron y en muchos casos transcriben sus explicaciones con mucho detalle. Algunos hicieron búsquedas en archivos y hemerotecas, no siempre con resultados significativos. Una estudiante tuvo la suerte de haber elegido una carta de visita realizada por un fotógrafo afincado en Valls (R. Rozada) a quien el Archivo y Museo Histórico Local dedicó una exposición en el período que realizaba el trabajo. Por tanto pudo acceder a una amplia información histórica sobre este profesional. De hecho, Jep Martí, director del Archivo Municipal de Valls, es el investigador más acreditado de la provincia de Tarragona sobre fotografía del s. XIX. 
La mayoría de análisis de los estudiantes únicamente se apoyaban en las memorias familiares, lógicamente más accesibles. Es muy relevante que todas sus explicaciones sean presentadas como informaciones verídicas, como datos históricos. Un caso extremo sería, tal como sugerimos, la explicación proporcionada por la vendedora callejera de fotografias antiguas que decía reconocer como familiares suyos a las personas que aparecen en los retratos que está dispuesta a vender por un precio más que reducido. Dicha información se expuso como información cierta, sin reticencias.

Lo más interesante es cómo estos relatos de los propios familiares se centran en unos temas y no en otros. Un aprendizaje exitoso hubiera sido advertir cómo esas selecciones se hacen desde el presente, ya que son operaciones maravillosamente significativas de la memoria. Por ejemplo el relato familiar respecto de la Fig. 2. (hijos de Fusté Doménech) se basa reiteradamente en expresar que la familia se encuentra vinculada a las actividades artísticas, musicales y teatrales, desde siempre. Que dicha actividad se ha llevado a cabo incluso en tiempos de guerra y que las mujeres de la familia han sido plenamente activas en esta actividad artística. Esta es una parte de la transcripción del relato familiar respecto de la niña que aparece en la fotografía:

"En la imatge que he escollit, surt la meva besàvia i els seu germà petit. La meva besàvia es deia Pepita Fusté Domenech, a la fotografia deuria de tindre uns 10 anys aproximadament, $i$ va néixer el 1920, és la penúltima de 10 germans. Va fer teatre, ballarina i va ser còmica en temps de guerra, cantava sarsueles i va cantar un temps a la Ràdio de Reus. La meva àvia em va explicar una anècdota en la que Marco Redondo, un conegut bariton espanyol especialitzat en el popular gènere líric de la sarsuela, la volia prendre per fer-la una bona cantant però els seus pares es van negar, sobretot el seu pare."

Desde luego que ser actriz cómica en tiempo de guerra, con a penas dieciséis o diecisiete años, constituye toda una proeza. Independientemente de si los documentos históricos corroboraran o no dicha historia, no deja de ser una verdad de memoria, que en el presente articula un relato con su sentido y su verdad. No olvidemos que la oyente del relato es una estudiante de una escuela de arte, y la abuela elabora la construcción de memoria en función de esta interlocutora.

La época actual está marcada, entre otras muchos aspectos, por el debate en torno a lo que algunos han venido a denominar la "posverdad" (Keyes, 2004; Marzal Felici; Casero Ripollés, 2017). El conflicto entre lo objetivo y lo subjetivo, al igual que entre lo cierto y lo verosímil, ha existido siempre. Pero en nuestra época nos sentimos especialmente preocupados por la difusión de relatos atractivos, emocionalmente verosímiles, que muchas veces no se fundamentan en datos objetivos, en documentos, en estadísticas contrastadas. Las instituciones políticas y los medios de comunicación en los que habíamos confiado hasta ahora, difunden frecuentemente relatos que ignoran soberanamente la persecución de la objetividad. La historia es un terreno abonado para la imposición de relatos verosímiles, no siempre bien contrastados. Por ejemplo, la sociedad española está viviendo actualmente un tenso debate ideológico sobre la relectura de la etapa de la Transición (1975-1982). Los partidos políticos y los medios de comunicación enfrentan relatos sobre este período, pero pocas veces invocando datos, estadísticas o documentos. Nos pareció muy interesante, en el momento de compartir los trabajos de nuestros alumnos sobre sus fotografias familiares, estimular de nuevo su conciencia crítica, evidenciando que algunas de sus verdades sí están basadas en datos históricos, pero muchas otras sólo en memorias familiares, que nacen de las 


\section{"Memoria versus historia en tu propio álbum familiar"}

leyes del presente, y que deben ser entendidas como memorias, no como historia. Todos tendemos a otorgar estatus de verdad a un relato bien construido por un sujeto desde el presente, sin embargo nuestra obligación científica es contrastarlo con certezas o, en todo caso, indicar su valor de memoria, no de historia.

En otro orden muy distinto, nos resulta interesante proponer una última reflexión a propósito de este ejercicio con retratos familiares, una reflexión en relación a las condiciones del trabajo docente y las tensiones que generan los currículos oficiales y sus marcos legislativos. Todos los niveles educativos tienen sus dificultades, los estudios profesionales de fotografía son un buen ejemplo de un campo de batalla muy complejo, donde la administración a través del currículum establece unas condiciones que necesariamente hemos de debatir en profundidad.

Este ejercicio que he descrito trata de ser una respuesta a un doble requerimiento que establece el currículum de la asignatura de la Historia de la Fotografía en los actuales Ciclos Formativos de Grado Superior de Fotografía. Como en otros niveles educativos, lo más característico es que el currículum oficial cada vez dota de menos tiempo al profesor y a los alumnos para desarrollar la asignatura y, paradójicamente, las demandas de resultados en el aprendizaje son cada vez más elevadas y complejas. Los estudios profesionales de fotografía se implantaron en España (de forma oficial y para el conjunto del territorio) dentro del marco legislativo de la LOGSE. Su currículum se desarrolló en Cataluña en el año 1997 y la asignatura de Historia de la Fotografía disponía de $150 \mathrm{~h}$. lectivas para desarrollar los contenidos. El siguiente marco normativo, vinculado a la LOE, data de 2012 y se implantó en Cataluña en la mayoría de centros en el curso 2014/15. En el nuevo contexto, la asignatura de Historia de la Fotografía se ve reducida a 99 h., de las cuales solo 82 h. se pueden dedicar a los contenidos propios de Historia de la Fotografía. En consecuencia, el tiempo de trabajo en el aula ha quedado reducido de $150 \mathrm{~h}$. a $82 \mathrm{~h}$., prácticamente a la mitad. Todo respira un mandato social: las cosas han de ir de prisa, los títulos académicos se han de ofrecer cada vez en menos cursos, convencidos como estamos a nivel social de que lo que verdaderamente nos capacita como profesionales (y como adultos) es el mundo de la empresa, y la escuela debe ser un trámite cada vez más breve y, además, con cada vez más horas de prácticas en empresa y menos tiempo en el aula.

En los dieciséis cursos que impartimos el ciclo formativo LOGSE de fotografía en mi centro educativo (EADT), en tres ocasiones distintas propuse un ejercicio a los estudiantes que guardaba cierta relación con el que he analizado en esta comunicación. En aquella otra propuesta pedagógica, una vez desarrollado en el aula el caso del fotógrafo J.H. Lartigue (que de alguna forma es el paradigma de fotógrafo doméstico considerado al mismo tiempo un artista de referencia), proponía a los estudiantes que observaran las colecciones de fotografías domésticas de su propia familia, que analizaran qué temas fotográficos son mas frecuentes, qué ideas se repiten, a través de las imágenes, a lo largo de varias generaciones (la suya, la de sus padres, la de sus abuelos...). El trabajo se apoyaba también en la lectura de algún ensayo sobre la significación global del álbum familiar fotográfico: Don Slater (1995) o John Roberts (1998) fueron los autores de la lectura propuesta en años distintos. Aquel trabajo comportaba una mayor dedicación temporal, pues implicaba una revisión algo más amplia de las colecciones fotográficas familiares, más un texto escrito por el alumno comentando los contenidos globales de esta colección, apoyándose en la lectura de un ensayo sobre el tema. La opción pedagógica estos dos últimos cursos LOE, en cambio, se limita a proponer una pequeña investigación sobre una única fotografía familiar, sin integrar lecturas obligatorias. Trato, pues, de dar una respuesta a unas nuevas circunstancias en que los tiempos de aprendizaje están extraordinariamente comprimidos. 
Por otra parte, el trabajo propuesto a los alumnos en los dos últimos cursos, a pesar de su formato mucho más sintético, trata también de dar respuesta a una exigencia prácticamente utópica del nuevo currículum académico LOE de Historia de la Fotografía. El primer currículum LOGSE del año 1997 establecía como uno de los objetivos terminales de la asignatura (por tanto sujetos a evaluación) "consultar documentación específica sobre un determinado tema de historia de la fotografia, analizarla y valorarla críticamente" (DOGC. 26/6/1997, p. 7219). Así pues la lectura de libros especializados de historia de la fotografía o quizá una visita esporádica a un archivo, siempre valorando críticamente la información recibida, cumplía perfectamente este objetivo. El nuevo currículum LOE (en Cataluña oficializado en un último decreto del año 2016) establece como un objetivo evaluable de la asignatura algo, pienso yo, apabullante: "desarrolla una metodología adecuada en la elaboración de trabajos de investigación histórica de la fotografia" (DOGC. 29/4/2016, p. 287). Realizar trabajos de investigación histórica con una metodología adecuada es una competencia propia de un historiador (formado en un grado de historia), no de un futuro profesional de la fotografía que recibe unos conocimientos básicos de historia en una asignatura cada vez más menguante. Investigar implica generar conocimiento donde no existía y, en el caso de la investigación histórica, implica sobre todo acudir a las fuentes primarias: a los documentos fotográficos, a los archivos, a las publicaciones de aquella época, a la entrevista de sus protagonistas o sucesores, etc. A mi criterio, algo fuera de lugar en este nivel educativo. Es cierto que la Inspección Educativa, por suerte, no persigue a los docentes con el texto del currículum oficial cual talibán o inquisidor invocando las escrituras sagradas. Afortunadamente no he presenciado nunca esta situación. Pero el texto curricular, en mi opinión, adolece de una reflexión adecuada sobre los objetivos propios de cada nivel educativo, del contexto y de los recursos temporales de los que se dispone. Evidentemente, la actividad que propongo a los estudiantes buscando una fotografia familiar propia de inicios del $\mathrm{s}$. XX, documentándose sobre ella, acudiendo a sus protagonistas o a sus descendientes es, objetivamente, una investigación histórica en toda regla. Discernir, además, críticamente qué es información histórica y qué es un relato de memoria en relación a ese documento fotográfico sería la excelencia. La cuadratura del círculo.

\section{Conclusiones}

Como docente que ha diseñado y desarrollado esta actividad con los alumnos no me corresponde a mí una evaluación objetiva de la misma. Me ha parecido, sin embargo, oportuno relatarla y proponer mis observaciones al respecto. Pienso que es una forma de abrir el debate sobre las circunstancias de la enseñanza de la historia de la fotografía, al menos en este nivel educativo. En este ejercicio, como he tratado de exponer, se visualizan dos conflictos interesantes. El primero es de orden historiográfico y tenía que ver con la articulación de la historia y de la memoria como fuentes de conocimiento del pasado, y de la confusión significativa que se da entre ellas en un trabajo escolar. Esta confusión es frecuente en muchos otros ámbitos culturales, quizá propia de una época en que la objetividad tiende a ser substituida por el relato emocional.

Por otra parte, el diseño del ejercicio académico nace de la necesidad de dar respuesta a objetivos curriculares de la asignatura casi inalcanzables, sobre los que me parece oportuno abrir un debate. En todo caso al lector de esta comunicación le corresponde una opinión más objetiva sobre el éxito o fracaso de la actividad pedagógica expuesta y sobre si existe o no una exigencia desmedida en los currículos oficiales de Historia de la Fotografía para este nivel educativo. 


\section{Referencias}

ANTICH, X. (2011). "Del 'mal d'arxiu' a la 'febre d'arxiu'. La noció d'arxiu en la cultura contemporània." en Lligall, núm. 32. pp. 13-41). http://www.arxivers.com/index.php/documents/publica cions/revista-1ligall-1/1ligall-32-1/995-02-del-mal-d-arxiu-a-lafebre-d-arxiu-la-nocio-d-arxiu-en-la-cultura-contemporania-2/file [consulta 11 de julio de 2015]

Cataluña/España. Departamento de Educación de la Generalitat de Catalunya. Decreto 137/1997, por el cual se establece el currículum de los ciclos formativos de formación específica de grado superior de artes plásticas y diseño en gráfica publicitaria, en ilustración y en fotografía artística de la familia profesional de diseño gráfico DOGC. de 26 de junio de 1997, Núm. 2419, pp. 7208-7223.

Cataluña/España. Departamento de Educación de la Generalitat de Catalunya. Decreto 245/2016, de 26 de abril, por el cual se establece el currículum de los ciclos formativos de grado medio y grado superior de artes plásticas y diseño de la familia profesional artística de comunicación gráfica y audiovisual, DOGC de 29 de abril de 2016, núm. 7110, pp. 1-438.

COSCI, L.D. (2012). "Caminos de rememoración. La memoria y la construcción del conocimiento histórico en la hermenéutic de Paul Ricoer” en Cifra-6, agosto 2012, pp. 29-40. http://fhu.unse.edu.ar/carreras/rcifra/danielcosci.pdf [consulta 3 de agosto de 2017]

CROSS, K., PECK, J. (2010). "Editorial (Special Issue on Photography, Archive and Memory,)" [en línia] en Photographies, 3: 2 , 127 - 138) http://dx.doi.org/10.1080/17540763.2010.499631 [consulta 20 de febrero de 2011]

España, Real Decreto 1432/2012, de 11 de octubre, por el que se establece el título de Técnico Superior de Artes Plásticas y Diseño en Fotografía perteneciente a la familia profesional artística de Comunicación Gráfica y Audiovisual y se aprueban las correspondientes enseñanzas mínimas, BOE de 3 de noviembre de 2012, pp. Núm. 265, pp. 77527-77546.

FREUND, G. (1974). La fotografía como documento social. Barcelona: Editorial Gustavo Gili. 2001. <Título original: "Photographie et Societé">

HIRSCH, M. (2008). “The Generation of Postmemory” en Poetics Today, num. 29,1 (pp 103-128) http://www.columbia.edu/ mh2349/papers/generation.pdf [consulta 8 de noviembre de 2014]

KEYES, R. (2004). The Post-Truth Era: Dishonesty and Deception in Contemporary Life. New York (EUA): R. Keyes ISBN 9781429976220 .

LAVABRE, M. C. (2006) "Sociología de la memoria y acontecimientos traumáticos” en Aróstegui, J.; Godicheau, F. (eds.) Guerra Civil (mito y memoria). Madrid: Marcial Pons Ediciones de Historia

MARZAL FELICI, J., CASERO RIPOLLÉS, A. (2017). "Editorial. El fotoperiodismo en la era de la posverdad”. En adComunica. Revista Cientifica de Estrategias, Tendencias e Innovación en Comunicación, $n^{\circ} 13$. Castellón: Asociación para el Desarrollo de la Comunicación ad Comunica y Universitat Jaume I, pp. 11-17. http://dx.doi.org/10.6035/2174-0992.2017.13.1 [consulta 3 de agosto de 2017]

MASSOT, J. (2012). "La memoria històrica és un oxímoron (Francesc-Marc Àlvaro, que publica entre la mentida i l'oblit)" en $L a$ Vanguardia, 28 de marzo de 2012, p.33.

NEWHALL, B. (1982, 2001). Historia de la fotografia. Barcelona: Editorial Gustavo Gili, 2002. <Título original: "The History of Photography from 1839 to the Present (Completely Revised and Enlarged Edition)"> 
NORA, P. (1984). "Entre Mémoire et Historie: la problématique des lieux, XVII-XLII" en Nora. P. Les Lieux de Mémoire (volumen 1, La République). Paris: Gallimard.

O'BRIEN, M. (2010). "Mum's Got To Sell The House" en Photographies, 3: 2, pp. $189-203<$ www: http://dx.doi.org/10.1080/17540763.2010.499613> [consulta 20 de febrero de 2011]

ROBERTS, J (1998). "Jo Spence: la fotografia, la autoafirmación y lo cotidiano" en VVAA. (2005). Jo Spence: más allá de la imagen perfecta. Fotografia, subjetividad, antagonismo. Barcelona, MACBA.

ROYAL COLLECTION TRUST (UK) (sf.). Prince Sergei and Prince George of Leuchtenberg $1859<$ https://www.royalcollection.org.uk/collection/2907696/prince-sergei-and-prince-george-of-leuchtenberg $>$ [consulta 1 de agosto de 2017]

SLATER, D. (1995). "La fotografía doméstica y la cultura digital” en Lister, Martin (ed.) (1995). Imagen fotográfica en la cultura digital. Barcelona: Paidós, 1997, pp.173-195.

SOUGEZ, M.L. (1996). Historia de la Fotografia. Barcelona: Càtedra. 


\section{ANEXO 1 (encargo de la actividad pedagógica a los alumnos)}

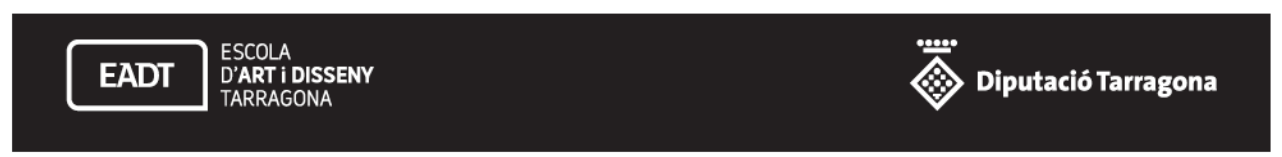

Curs 2016/17 / C.F.G.S. de Fotografia / Mòdul: Història de la Fotografia $1 /$ Unitat de Prog. Núm 3

Treball:

Carta de visita $i$ retrat a finals del s. XIX $\mathbf{i}$ i inicis del s. $X X$

(petita investigació)

> > data presentació dijous 23 de febrer de 2017

>la qualificació d'aquest treball es ponderarà com el $\mathbf{4 0 \%}$ de la nota d'aquesta unitat de programació (el 60\% restant correspondrà a un examen)

$>$ El treball té per objectiu que l'alumne aprofundeixi en el coneixement de les característiques (tècniques $i$ formals) del retrat fotogràfic comercial d'ús privat a finals del s. XIX i inicis del s. XX, els seus objectius estètics $i$ conceptuals, $i$ també els seus condicionants socials $i$ històrics. Es pretén també que l'alumne practiqui $i$ aprofundeixi les seves capacitats de redactar un comentari d'una fotografia, en aquest cas un retrat comercial. En tercer lloc, es pretén, també, que l'alumne elabori una recerca pròpia d'història de la fotografia (adequada a un nivell de Cicle Formatiu de Grau Superior), consultant el seu arxiu fotogràfic familiar, cercant documentació publicada en relació a fotògrafs locals -propers- del període i, eventualment, faci una recerca en fonts primàries, com ara arxius $i$ hemeroteques, en relació a fotògrafs d'aquest període, així com amb els familiars que el puguin informar de la fotografia

\section{Indicacions sobre el procés de treball}

1. Recerca de la imatge/imatges

Cal que feu una recerca en els fons fotogràfics familiars -família extensa- i veure quins retrats familiars es conserven en còpies d'època del període 1860-1936, aproximadament. Caldrà que descriviu molt breument els fons fotogràfics familiars que heu localitzat i que trieu un retrat en particular per fer un comentari detallat.

- I'ideal és que trieu un retrat del qual conserveu una còpia "original" d'època i que pugueu portar un dia a classe (porteu-la, molt millor, dins d'una funda de plàstic que la preservi adequadament).

- si no és possible disposar de l'original de forma permanent, treballeu sobre una reproducció (millor si és un escàner fet per vosaltres mateixos, millor que disposeu d'una reproducció de l'anvers i el revers de la imatge amb bona resolució).

- si és absolutament impossible localitzar un retrat fotogràfic d'aquest període en els àlbums de la vostra família extensa, tot i haver fet l'esforç de recerca, us suggereixo dues alternatives (només com a darrera solució): 
- adquirir un retrat antic -el preu de mercat pot estar al voltant de $6 €$ - a col-leccionistes o en "mercats de vell" i inventar-se que és un familiar (molts artistes/fotògrafs contemporanis treballen sobre la ficció, fins i tot la ficció de la pròpia biografia i de la pròpia memòria).

- comentar un retrat d'aquesta època d'un desconegut ja publicat i assenyalar la font de publicació i que es tracta d'una persona desconeguda.

\section{Cercar informació sobre la fotografia}

- Entrevisteu als vostres familiars en relació a la persona que apareix a la fotografia (la seva vida) i, especialment, on es va fer la fotografia i per què. Què en sabeu del retratat, de la vostra relació familiar amb ell, de la data i el lloc en què es van fer la fotografia. Busqueu informació publicada o documents que us donin més informació sobre la persona retratada.

Redacteu aquesta informació. Considereu la possibilitat de transcriure literalment algunes explicacions concretes dels vostres familiars, paraula per paraula, si us semblen interessants (indicant l'informant $i$ la data i lloc de la vostra entrevista). Considereu la possibilitat de diferenciar la informació històrica (informació objectiva sobre el passat) i la informació de memòries familiars (els records subjectius transmesos des del present respecte el passat).

- Cerqueu informació sobre el fotògraf que va fer la imatge. Seria convenient triar un retrat que en el revers (o en l'anvers) aparegués el seu nom professional. Busqueu informació en publicacions diverses (webs i blogs a internet, revistes i llibres). Per exemple podeu investigar a través del directori "Cilifford" (http://www.fotoconnexio.org/clifford/). Eventualment plantegeu-vos fer una recerca en fonts primàries, per exemple anar a l'arxiu històric del vostre municipi i buscar informació sobre aquest fotògraf (si hi ha més fotografies, si apareix en els documents de llicències comercials, si apareix en el cens municipal) o bé consultar en les hemeroteques buscant a les revistes anuncis d'aquests fotògrafs o mencions a les notícies de l'època.

\section{Presentació del treball: continguts (apartats)}

La presentació del treball es farà simultàniament de tres formes:

$>$ a través d'un text escrit que portareu imprès els dia 23 de febrer i el lliurareu al professor

$>$ a través d'un text publicat per vosaltres en un fòrum específic que obrirem a l'aplicatiu Moodle (o bé publiqueu el text sencer del vostre treball, o bé un resum de cada apartat). Haureu de publicar una reproducció de la imatge comentada.

>també a través d'una exposició breu ( 5 minuts) que fareu a classe compartint amb els companys el que heu investigat i I'anàlisi que feu d'aquesta fotografia

El text del treball ha d'explicar: 


\section{1- El procés de recerca}

Expliqueu de forma ordenada el vostre procés de recerca per elaborar el treball. Expliqueu el procés de recerca d'imatges (dels retrats) i de les troballes que heu fet. Comenteu per què heu fet la tria d'una determinada imatge per analitzar. Expliqueu el procés de recerca de documentació sobre el retratat $\mathrm{i}$ sobre el fotògraf. Exposeu tant les recerques que han estat exitoses com aquelles que no han donat resultats (tant sobre la recerca de fotos familiars com sobre la informació sobre el familiar i el fotògraf). (extensió recomanada d'un full; uns 2000 caràcters)

\section{2.- Anàlisi i comentari de la imatge}

Comenteu amb detall la imatge. Dediqueu un apartat a la contextualització del retratat (qui és, què en sabeu) i a la contextualització del fotògraf (qui és, que se sap d'ell, que heu descobert sobre ell). Dediqueu un altre apartat a comentar els aspectes fotogràfics i estètics: quines mesures té la còpia, amb quin procediment s'havia fet el negatiu i la còpia, i quines característiques visuals té la imatge -enquadrament, il-luminació, atrezzo, gest del retratat-. Valoreu l'interès històric, estètic i personal-familiar de la imatge (extensió recomanada de dos fulls, uns 4000 caràcters).

\section{3.- Bibliografia i fonts documentals}

citar correctament les publicacions consultades (llibres, revistes, webs) i fer referència breu a d'altres fonts documentals (arxius familiars, arxius públics, hemeroteques 